\title{
Low Plasma Ascorbate Levels in Type 2 Diabetic Patients With Adequate Dietary Vitamin C
}

\author{
Abhishek Bansal ${ }^{1} \quad$ Chetana P. Hadimani ${ }^{2, \odot}$ \\ ${ }^{1}$ Department of Biochemistry, KLE Academy of Higher Education \\ and Research (KAHER), J.N. Medical College, Belagavi, Karnataka, \\ India
}

J Lab Physicians 2021;13:139-143.

\begin{abstract}
Address for correspondence Chetana P. Hadimani, MBBS, MD, PGDHPE, Department of Biochemistry, KLE Academy of Higher Education and Research, J.N. Medical College, Belagavi 590010, Karnataka, India (e-mail: chetanaph@gmail.com).
\end{abstract}

\begin{abstract}
Keywords

- type 2 diabetes

mellitus

- dietary vitamin C

- plasma ascorbate

- FBS
\end{abstract}

\section{Introduction}

Diabetes is a clinical metabolic disorder with increased blood glucose levels because of total or comparative deficiency of insulin. Factors contributing to hyperglycemia are either reduced insulin secretion or decreased glucose utilization. ${ }^{1}$ According to the International Diabetes Federation

published online June 16, 2021
DOI https://doi.org/ $10.1055 / \mathrm{s}-0041-1730751$ ISSN 0974-2727
Atlas 2017, 72.9 million Indians are suffering from diabetes. ${ }^{2}$ Normal metabolism of cells produces reactive oxygen species (ROS). They have a beneficial effect on the functioning of cells and, if they are increased, result in excessive lipid peroxidation, leading to the damage of proteins and DNA. ${ }^{3}$

The rate of ROS production depends on hyperglycemia, insulin resistance, and obesity, which are risk factors of
(C) 2021. The Indian Association of Laboratory Physicians. This is an open access article published by Thieme under the terms of the Creative Commons Attribution-NonDerivative-NonCommercial-License, permitting copying and reproduction so long as the original work is given appropriate credit. Contents may not be used for commercial purposes, or adapted, remixed, transformed or built upon. (https://creativecommons.org/licenses/by-nc-nd/4.0/). Thieme Medical and Scientific Publishers Pvt. Ltd. A-12, 2nd Floor, Sector 2, Noida-201301 UP, India 
metabolic syndrome. ${ }^{4}$ Insulin resistance, $\beta$-cell dysfunction, and type II DM act as the root of increased oxidative stress and impaired antioxidant defense mechanism resulting in micro- and macrovascular dysfunction..$^{5-7}$

Ascorbic acid is a water-soluble antioxidant and scavenge free radicals. It acts as a reducing agent in hydroxylation reactions and prevents from oxidative damage of biological macromolecules. ${ }^{8}$ As per WHO (World Health Organization) recommendation, recommended daily allowance (RDA) of vitamin C for adults is $45 \mathrm{mg} / \mathrm{d}$. People who consume low amount of fruits and vegetables have a higher risk of vitamin $\mathrm{C}$ deficiency. In general, fruits and vegetables consumption determines the vitamin $C$ status. ${ }^{9}$ With sodium-dependent vitamin $C$ transporter 1 , intestinal absorption of ingested vitamin $\mathrm{C}$ occurs as ascorbic acid and by facilitated diffusion via GLUT 2 (glucose transporter 2) and GLUT 3 transporters, dehydroascorbic acid (DHA) is transported. Further ascorbic acid is transported by GLUT1 and GLUT2, which facilitates uptake of DHA. ${ }^{10}$ Hyperglycemia results in impaired uptake of vitamin $C$ into the cell. ${ }^{11}$

In a study the possible interactions between glucose and vitamin $C$ transport in the human intestine were evaluated. Ascorbate uptake was inhibited by increasing concentrations of glucose. ${ }^{12}$ Several studies state that in diabetes there is increased oxidative stress and increase in requirement of vitamin C. ${ }^{13-18}$ Some studies reported that there was no association with plasma ascorbate levels in diabetic patients. ${ }^{19-21}$

Although several mechanisms have been explained for low vitamin C levels among the type 2 diabetes mellitus (T2DM), dietary vitamin $C$ intake was not considered. This present study was conducted to compare the plasma ascorbate levels in type 2 diabetic patients and controls with an adequate dietary intake of vitamin $\mathrm{C}$, which was evaluated using a validated food frequency questionnaire ( - Supplementary Table S1 [online only]).

\section{Materials and Methods}

The present community-based cross-sectional study was conducted at KLE's Dr. Prabhakar Kore Charitable Hospital, Belagavi, India from January 2019 to December 2019. Seventy-five consented T2DM patients who were on treatment with oral hypoglycemic drugs and consuming adequate vitamin $C$ in diet were taken in the study and 50 healthy controls equitably matched for age, gender between 40 and 70 years with dietary intake of vitamin $C$ were compared. Subjects with type $1 \mathrm{DM}$, endocrine disorders, malabsorption syndrome, who have undergone previous gastrointestinal surgeries, smokers, and chronic alcoholics were excluded from the study. The study was approved by the Institutional Ethical and Research Committee.

Adequate dietary intake of vitamin $C$ was estimated by food frequency questionnaire, which was validated with a cohort of individuals with T2DM subjects. ${ }^{22,23}$ Prevalidation of the questionnaire was performed. Data regarding dietary recall of intake of food over a recent week's time was recorded with all the details. Dietary intake was marked by the subject and assembled through a structured interview. Average consumption of vitamin $C$ was quantified from the questionnaire. As per WHO, intake of vitamin C more than $35 \mathrm{mg} / \mathrm{d}$ is sufficient for the Indian population, hence subjects consuming more than $35 \mathrm{mg} / \mathrm{d}$ of vitamin C were included. Fasting blood sugar was estimated by glucose oxidase and peroxidase method. ${ }^{24}$ Estimation of ascorbic acid was done by using 2, 4 dinitro phenyl hydrazine method using Single Beam UV-visible spectrophotometer. In this procedure, ascorbic acid is first oxidized to DHA and 2,3-diketogulonic acid with the formation of a colored product that absorbs at $520 \mathrm{~nm}$. This method, measures the total vitamin $\mathrm{C}$ content of the sample because ascorbic acid, DHA, and diketogulonic acid are also measured and is subject to interference from amino acids and thiosulfates. ${ }^{25}$ As per guidelines of the National Institute of Nutrition, Hyderabad, normal level of plasma ascorbate is 0.4 to $2.0 \mathrm{mg} / \mathrm{dL}$ and deficiency is below than $0.2 \mathrm{mg} / \mathrm{dL}$. The diagnosis of T2DM was established at fasting blood glucose value of more than or equal to $126 \mathrm{mg} / \mathrm{dL}{ }^{8}$

Statistical analysis was performed using SPSS software, version 20.0 for Windows; IBM Corporation, Software Group, Route 100, Somers, New York 10589. Continuous variables were expressed as mean \pm standard deviation (SD). An independent $t$-test was used to compare the parameters in case and control population. $p<0.05$ was considered statistically significant. The Karl Pearson's coefficient test was used to find out the correlation between the parameters.

\section{Results}

In this study, a total of 125 subjects were evaluated. In them 75 subjects were with T2DM and 50 were healthy controls. However, 25 diabetic subjects were excluded from this study as shown in - Fig. 1. The overall distribution of subjects is shown in - Table 1.

- Table 2 shows the comparison of levels of dietary intake of vitamin C, fasting blood sugar (FBS), and plasma ascorbate levels among the type 2 diabetic patients and controls in the study population. The mean \pm SD levels of dietary intake of vitamin C, was $57.28 \pm 18.37$ per day in diabetics, which was showing no statistical difference as compared with controls with a mean value of $57.28 \pm 22.62$ per day. The mean \pm SD levels of FBS was $160.55 \pm 57.63 \mathrm{mg} / \mathrm{dL}$ which was significantly increased in diabetic subjects as compared with controls with FBS $84.46 \pm 11.156 \mathrm{mg} / \mathrm{dL}$. The mean \pm SD level of plasma ascorbate levels in diabetic subjects was $0.22 \pm$ $0.12 \mathrm{mg} / \mathrm{dL}$, which was significantly lower as compared with controls with plasma ascorbate level of $0.47 \pm 0.15 \mathrm{mg} / \mathrm{dL}$ with $p<0.05$.

Further correlation was done in diabetic and control group with FBS and plasma ascorbate levels by Karl Pearson's correlation coefficient method. In diabetic subjects insignificant positive correlation was observed between these parameters with $r$-value 0.168 and $p$-value 0.245 , whereas in nondiabetic subjects there was no correlation between FBS and plasma ascorbate levels with $r$-value 0.007 and $p$-value 0.961 as shown in - Fig. 2. 


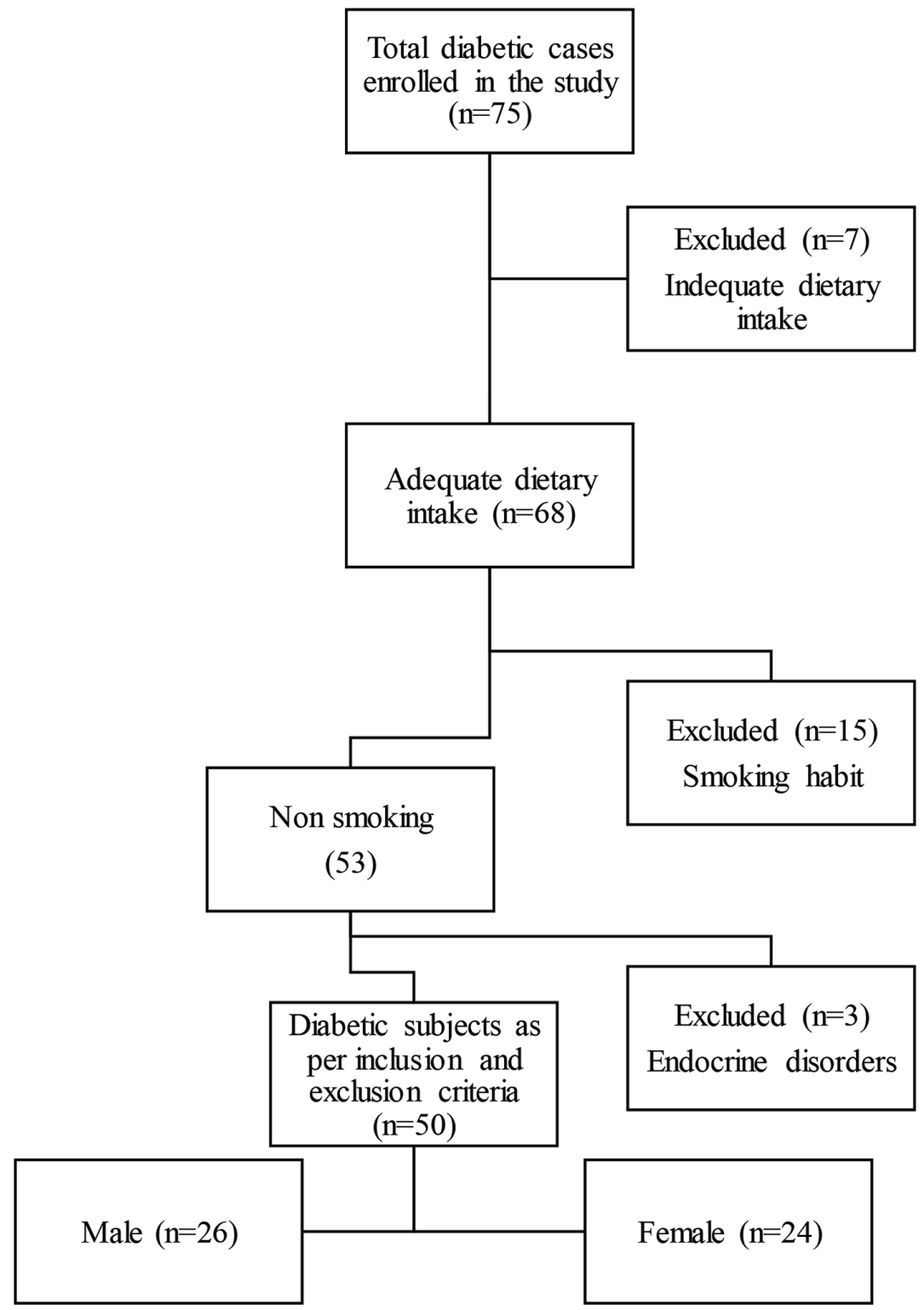

Fig. 1 Participants' flow diagram of T2DM patients. T2DM, type 2 diabetes mellitus.

Table 1 Distribution of type-2 diabetic subjects and controls by gender

\begin{tabular}{|l|l|l|l|}
\hline Gender & Diabetic & Nondiabetic & Total \\
\hline Female & 24 & 24 & 48 \\
\hline Male & 26 & 26 & 52 \\
\hline Total & 50 & 50 & 100 \\
\hline
\end{tabular}

Table 2 Comparison of dietary intake of vitamin C, FBS, and plasma ascorbate levels in diabetic and nondiabetic patients

\begin{tabular}{|c|c|c|c|c|c|c|}
\hline & \multicolumn{2}{|c|}{ Diabetic } & \multicolumn{2}{|c|}{ Nondiabetic } & \multirow[t]{2}{*}{$t$-Value } & \multirow[t]{2}{*}{$p$-Value } \\
\hline & Mean & Std. deviation & Mean & Std. deviation & & \\
\hline $\begin{array}{l}\text { Dietary intake of vitamin } \\
\mathrm{C}(\mathrm{RDA}>35 \mathrm{mg} / \mathrm{d})\end{array}$ & 57.28 & 18.37 & 57.28 & 22.62 & 0.001 & 0.999 \\
\hline FBS(70-110 mg/dL) & 160.55 & 57.63 & 84.46 & 11.156 & 9.166 & $<0.001^{a}$ \\
\hline $\begin{array}{l}\text { Plasma ascorbate levels } \\
(0.4-2.0 \mathrm{mg} / \mathrm{dL})\end{array}$ & 0.22 & 0.12 & 0.47 & 0.15 & 9.06 & $<0.001^{\mathrm{a}}$ \\
\hline
\end{tabular}

Abbreviations: FBS, fasting blood sugar; RDA, recommended daily allowance.

asignificant at the 0.01 level. 

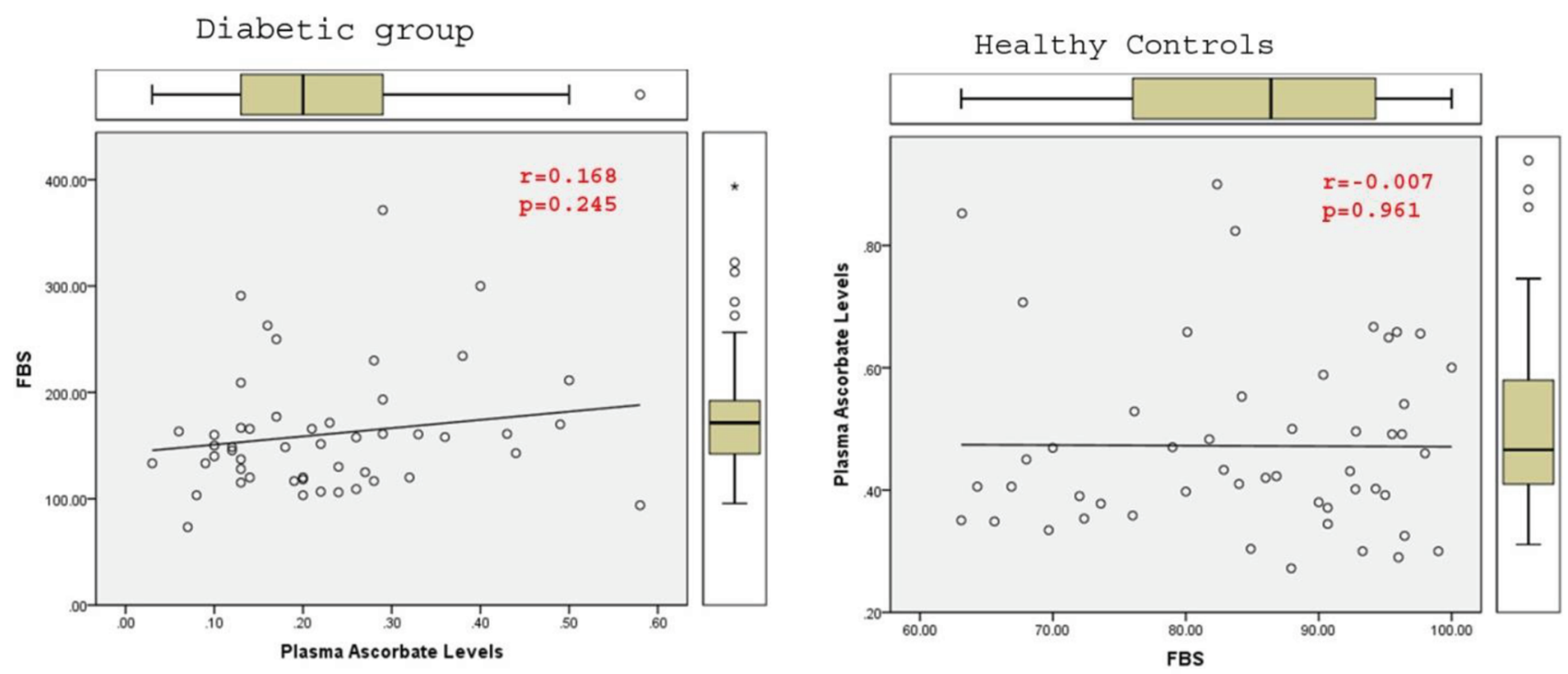

Fig. 2 Correlation between FBS and plasma ascorbate levels in diabetic subjects and healthy controls. FBS, fasting blood sugar.

\section{Discussion}

Dietary intake of antioxidative vitamin C plays a protective role in the prevention of oxidative damage in diabetics demanding increased requirement of vitamin $C$. In hyperglycemia cellular injury is due to oxidative stress induced by hyperglycemia. Weak defense system of the body fails to respond against ROS generation and causes imbalance between ROS and their protection that leads to oxidative stress. ${ }^{6,11}$ Vitamin C protects organs from damage in diabetes by three mechanisms that are, it has functioned as an antioxidant, inhibits the intracellular accumulation of sorbitol, and reduces the glycosylation of protein. ${ }^{11}$ Some studies suggested that supplementation of vitamin $C$ could be helpful to improve better insulin action and helps to control secondary complication of T2DM. ${ }^{26-31}$

In this cross-sectional study plasma ascorbate levels were assessed in 50 T2DM patients ( male $=26$, female $=24$ ) who were consuming adequate dietary vitamin $C$ and compared with 50 healthy controls from local community, Belagavi. We found that plasma ascorbate levels were significantly lower in diabetic subjects, even with adequate RDA for vitamin C as compared with controls with $p$-value $<0.0001$. The study showed vitamin $\mathrm{C}$ deficiency among diabetic patients compared with controls.

Similar to our results a study concluded that low ascorbate level in diabetes is a consequence of the disease itself and not due to inadequate dietary intake of vitamin C. ${ }^{32}$ Similar results were reported from many studies which showed that in diabetics due to increased oxidative stress vitamin $C$ levels were significantly low. This relationship was due to increased oxidative stress, which causes inflammation and dysglycemia and competitively inhibits ascorbic acid at the intestinal absorption level by high blood glucose levels. ${ }^{13-18}$ In contradicting with our results some of the studies stated that there was no difference in plasma ascorbate levels between T2DM patients and controls. ${ }^{19-21}$
Although plasma ascorbate levels were lower among diabetic subjects, we found an insignificant positive correlation between FBS and plasma ascorbate levels in T2DM with $r$-value 0.168 and $p$-value 0.245 . In contradicting to our results, some studies found significant negative association between FBS and plasma ascorbate levels. ${ }^{31,33}$ Further, between FBS and plasma ascorbate levels, there was no correlation in control groups $(r=0.007 ; p=0.961)$.

\section{Conclusion}

The present study demonstrates that even with an adequate dietary intake of vitamin C in T2DM patients, lesser plasma ascorbate levels are observed as compared with healthy controls. This necessitates increased demand and dietary advice to diabetic patients on the intake of vitamin $\mathrm{C}$ rich foods more than the RDA. Plasma ascorbate estimation in diabetic patients can be used as an additional investigation as a precaution to prevent vitamin $\mathrm{C}$ deficiency.

\section{Limitations}

The findings in the present study add to the limited sample size and only FBS levels were used to correlate with plasma ascorbate; further research with the inclusion of glycated hemoglobin value will indicate the degree of vitamin $\mathrm{C}$ deficiency with glycemic control.

\section{Ethical Clearance}

Approved by the Institutional Ethics Committee.

\section{Funding Source \\ Not applicable.}

\section{Conflict of Interest}

None. 


\section{References}

1 Hall JE, Guyton AC, Guyton AC, Hall JE, Cortical and brain stem control of motor function. In: Guyton AC, Hall JE, eds. Textbook of Medical Physiology. 11th ed. Philadelphia, PA: Elsevier Saunders;2011:685-697

2 Cho NH, IDF Diabetes Atlas. 8th ed; 2017 International Diabetes Federation

3 Lamb RE, Goldstein BJ. Modulating an oxidative-inflammatory cascade: potential new treatment strategy for improving glucose metabolism, insulin resistance, and vascular function. Int J Clin Pract 2008;62(7):1087-1095

4 Roberts CK, Barnard RJ, Sindhu RK, Jurczak M, Ehdaie A, Vaziri ND. Oxidative stress and dysregulation of NAD(P)H oxidase and antioxidant enzymes in diet-induced metabolic syndrome. Metabolism 2006;55(7):928-934

5 Shinde SN, Dhadke VN, Suryakar AN. Evaluation of oxidative stress in type 2 diabetes mellitus and follow-up along with vitamin E supplementation. Indian J Clin Biochem 2011;26(1):74-77

6 Halliwell B, Gutteridge J. Free radicals in biology and medicine; 2015. Available at: https://books.google.com/books?hl=en\&l$\mathrm{r}=\& \mathrm{id}=3 \mathrm{DlKCgAAQBAJ} \& \mathrm{oi}=$ fnd \&pg $=$ PP $1 \& \mathrm{dq}=6 .+$ Halliw ell+B,+Gutteridge+JM.+Free+radicals+in+biology+and+medicine.+Oxford+University+Press,+USA\%3B+2015.\&ots=boqB4 AonR\&sig=8jJpV5p6VRNg3MAomRm8cpYewBs. Accessed June 2, 2020

7 Fagbohun OF, Emma-Ok BO, Agboola FK. Kolawol BA, Onakpoy $\mathrm{OH}$, Odewole TO. Levels of trace elements and antioxidant vitamins in type 2 diabetic patients in Ile-Ife, Nigeria. Trends Med Res. 2016;12(1):26-31

8 Burtis C, Bruns D. Tietz fundamentals of clinical chemistry and molecular diagnostics-e-book; 2014. Available at: $\quad$ https://books.google.com/books?hl=en\&lr=\&id=p7XwAwAAQBAJ\&oi=fnd\&pg $=$ PP1 \&dq=8.\%09Burtis + C, + Ash wood+E,+Bruns+D,+Sawyer+B.+Tietz+fundamentals+of+clinical+chemistry,+6TH+ED.+United+States+of+America,+Saunders,+an+imprint+of+Elsevier+Inc.\%3B+2008\&ots=jm11gtXdZt. Accessed June 2, 2020

9 FAO, World Health Organization, Vitamin and Mineral Requirements in Human Nutrition. 2nd ed. World Health Organization; 2004 1-20

10 Lindblad M, Tveden-Nyborg P, Lykkesfeldt J. Regulation of vitamin C homeostasis during deficiency. Nutrients 2013;5(8):2860-2879

11 Pearson JF, Pullar JM, Wilson R, et al. Vitamin C status correlates with markers of metabolic and cognitive health in 50-year-olds: findings of the CHALICE cohort study. Nutrients 2017;9(8):831

12 Malo C, Wilson JX. Glucose modulates vitamin C transport in adult human small intestinal brush border membrane vesicles. J Nutr 2000;130(1):63-69

13 Shim JE, Paik HY, Shin CS, Park KS, Lee HK. Vitamin C nutriture in newly diagnosed diabetes. J Nutr Sci Vitaminol 2010;56(4):217-221

14 Gokhale NH, Acharya AB, Patil VS, Trivedi DJ, Thakur SL. A short-term evaluation of the relationship between plasma ascorbic acid levels and periodontal disease in systemically healthy and type 2 diabetes mellitus subjects. J Diet Suppl 2013;10(2):93-104

15 Aliyu M, Lawal M, Mojiminiyi F, Saidu Y, Bilbis LS. Serum antioxidant vitamin levels in non-insulin-dependent diabetes mellitus subjects in Sokoto, Nigeria. Biokemistri 2006;17(2):107-114

16 Ahmad M, Khan MA, Khan AS. Naturally occurring antioxidant vitamin levels in patients with type-II diabetes mellitus. J Ayub Med Coll Abbottabad 2003;15(1):54-57
17 Hisalkar P, Patne A, Fawade M. Assessment of plasma antioxidant levels in type 2 diabetes patients. Int Biol Med Res 2012;3(2):1796-1800

18 Wilson R, Willis J, Gearry R, et al. Inadequate vitamin C status in prediabetes and type 2 diabetes mellitus: associations with glycaemic control, obesity, and smoking. Nutrients 2017;9(9):997

19 Yamada H, Yamada K, Waki M, Umegaki K. Lymphocyte and plasma vitamin $C$ levels in type 2 diabetic patients with and without diabetes complications. Diabetes Care 2004;27(10):2491-2492

20 Merzouk S, Hichami A, Madani S, et al. Antioxidant status and levels of different vitamins determined by high performance liquid chromatography in diabetic subjects with multiple complications. Gen Physiol Biophys 2003;22(1):15-27

21 Firoozrai M, Nourmohammadi I, Khanaki K. Assessment of antioxidant vitamins retinol and $\alpha$-tocopherol in plasma and ascorbic acid in plasma and mononuclear leukocytes in type 2 diabetics. Int J Endocrinol Metab 2006;4:202:205

22 Santosh HN, David C. A food frequency questionnaire to determine the intake of vitamin C: a pilot validation study. Rom J Diabetes Nutr Metab Dis 2017;24(2):95-99

23 Longvah T, Ananthan R, Bhaskarachary K, Venkaiah K, Indian Food Composition Tables 2017. National Institute of Nutrition; 2017535

24 Burtis C, Ashwood E, Bruns D, Sawyer B, Tietz Fundamentals of Clinical Chemistry. 6th ed. Philadelphia, PA: Elsevier Saunders; 2008

25 Varley H, Gowenlock A, Bell M, Practical Clinical Biochemistry. Volume 2: Hormones, Vitamins, Drugs and Poisons. 5th ed. London: William Heinemann Medical Books Ltd; 1984 254-255

26 Dakhale GN, Chaudhari HV, Shrivastava M. Supplementation of vitamin $C$ reduces blood glucose and improves glycosylated hemoglobin in type 2 diabetes mellitus: a randomized, double-blind study. Adv Pharmacol Sci 2011;2011:195271

27 Godala MM, Materek-Kuśmierkiewicz I, Moczulski D, et al. Lower plasma levels of antioxidant vitamins in patients with metabolic syndrome: a case control study. Adv Clin Exp Med 2016;25(4):689-700

28 Rafighi Z, Shiva A, Arab S. Mohd Yousof R. Association of dietary vitamin $C$ and e intake and antioxidant enzymes in type 2 diabetes mellitus patients. Glob J Health Sci 2013;5(3):183-187

29 Odum EP, Ejilemele AA, Wakwe VC. Antioxidant status of type 2 diabetic patients in Port Harcourt, Nigeria. Niger J Clin Pract 2012;15(1):55-58

30 Carter P, Gray LJ, Talbot D, Morris DH, Khunti K, Davies MJ. Fruit and vegetable intake and the association with glucose parameters: a cross-sectional analysis of the Let's Prevent Diabetes Study. Eur J Clin Nutr 2013;67(1):12-17

31 Sinclair AJ, Taylor PB, Lunec J, Girling AJ, Barnett AH. Low plasma ascorbate levels in patients with type 2 diabetes mellitus consuming adequate dietary vitamin C. Diabet Med 1994;11(9):893-898

32 Varma V, Varma M, Sarkar PD, Varma A, Vyas S, Kulkarni R. Correlation of vitamin $C$ with Hba1c and oxidative stress in diabetes mellitus with or without nephropathy. Nat J Med Res 2014;4(2):151-155

33 Santosh HN, David C. Food frequency questionnaire to determine the intake of vitamin C: a pilot validation study. Rom J Diabetes Nutr Metab Dis 2017;24(2):95-99

34 Sinclair AJ, Taylor PB, Lunec J, Girling AJ, Barnett AH. Low plasma ascorbate levels in patients with type 2 diabetes mellitus consuming adequate dietary vitamin C. Diabet Med 1994;11(9):893-898

35 Longvah T, Anantan I, Bhaskarachary K, Venkaiah K, Indian Food Composition Tables. Hyderabad: National Institute of Nutrition, Indian Council of Medical Research; 2017 